\title{
Simulation and Analysis of Radio over Fiber (RoF) Systems using Frequency Up-Conversion Technique
}

\author{
Vimala Reddy \\ PG student \\ Department of EXTC \\ Thakur college of Engineering \& Technology
}

\author{
Lochan Jolly, PhD \\ Professor \\ Department of EXTC \\ Thakur college of Engineering \& Technology
}

\begin{abstract}
Radio-over-Fiber (RoF) technology is an integration of microwave and optical networks [1]. RoF technology uses optical fiber as a backend technology due to the enormous advantages offered by it. SCM-WDM RoF systems (Subcarrier based Wavelength division multiplexing RoF system) improves spectral efficiency with high dispersion tolerance [7]. The data to be transmitted is electrically modulated with an IF (Intermediate frequency)or a RF (Radio frequency) carrier and electrically multiplexed using a multiplexer these signals are further optically modulated using an optical modulator and multiplexed using WDM to exploit the high bandwidth offered by the optical fiber. A comparison between IF over fiber and RF over has been analyzed in terms of quality factor and BER (Bit error rate) in a RoF system. In which the IF over fiber shows better performance than RF over fiber in terms of BER and Quality factor. IF signals are up-converted using HBT (Hetero-junction bipolar transistor) electronic mixer in the remote antenna units to the RF frequencies with the help of LO (local oscillator) and transmitted wirelessly [27].
\end{abstract}

\section{General Terms}

Wireless communication systems, Optical fiber communication, Subcarrier multiplexing, Wavelength division multiplexing, Radio-over fiber systems.

\section{Keywords}

External optical Modulation, Frequency up-conversion, remote antenna units, IF based RoF system, RF based RoF system, HBT (Hetero-junction bipolar transistor).

\section{INTRODUCTION}

In today's era of ubiquitous connectivity or "communication anytime, anywhere and with anything". The demand to have broadband capacity wirelessly has put pressure on wireless communication systems to increase both their transmission capacity, as well as their coverage [1]. Research on millimeter waves has gained attention recently. High frequencies in the range of $\mathrm{GHz}$ have more bandwidth, hence their data carrying capacity are more, but they encounter more losses when they are transmitted wirelessly hence they cannot be transmitted long distances whereas the low frequency signals encounters less losses hence they can travel long distances. At high frequency associated losses are high. Hence, there is a need for a waveguide to carry these waves. The medium is nothing but optical fiber due to the low loss offered by them $(0.2$ $\mathrm{dB} / \mathrm{km}$ ) in $1550 \mathrm{~nm}$ band which is much smaller than any other medium can provide. In order to meet the ever increasing demand for larger transmission bandwidth. Wireless network based on radio over-fiber technologies is a very beneficial solution. It acts as a back-end technology for the transportation of microwave and millimeter waves [1].
$\mathrm{RoF}$ is a well-established technique for the distribution of wireless communication systems due to the larger bandwidth offered by optical fiber and the add drop facility offered by the WDM systems makes it suitable to add and drop any channels simultaneously during transmission through Optical add-drop multiplexers (OADMs) [8].RoF makes it possible to centralize the RF signal processing functions in one shared location (Central office), and then to use optical fiber to distribute the RF signals to the remote base stations (BS) from there they are transmitted wirelessly through the remote antenna units (RAUs), as shown in figure 1. By doing so, RAUs are simplified significantly, as they only need to perform optoelectronic conversion and amplification functions. The need for increased capacity per unit area leads to higher frequencies per unit area leads to higher operating frequencies, smaller radio cells and large no of BS. Therefore, cost-effective BS development is a key success to the market [18].

\subsection{Architecture of RoF system}

RoF systems are classified into three main categories

1. RFoF (Radio Frequency over Fiber)

2. IFoF (Intermediate Frequency over Fiber)

3. $\mathrm{BBoF}$ (Baseband signal over Fiber)

\subsubsection{Radio Frequency over Fiber}

In RF-over-Fiber architecture, an RF signal (analog waveform) with high frequency (greater than $10 \mathrm{GHz}$ with baseband data embedded in it) can be modulated with light waves.

\subsubsection{Intermediate Frequency over Fiber}

In IFoF architecture, a data carrying RF signal with frequency (less than $10 \mathrm{GHz}$ ) are modulated with light wave using either direct or external modulation before transmission over the optical link. Therefore, before radiation through the air at the remote base station this signal from IF frequency needs to be up-converted to RF level before transmitting them wirelessly through RAUs. IFoF scheme has exhibited a $2 \mathrm{~dB}$ better sensitivity than RFoF scheme [1].

\subsubsection{Baseband signal over Fiber}

In $\mathrm{BBoF}$ scheme a baseband signal is modulated with light wave and transmitted over optical fiber. Then, at the receiver end this baseband signal is detected and up-converted to RF level by up-conversion techniques. BBoF scheme exhibits better sensitivity than an IFoF scheme by $4 \mathrm{~dB}$ [1]. 


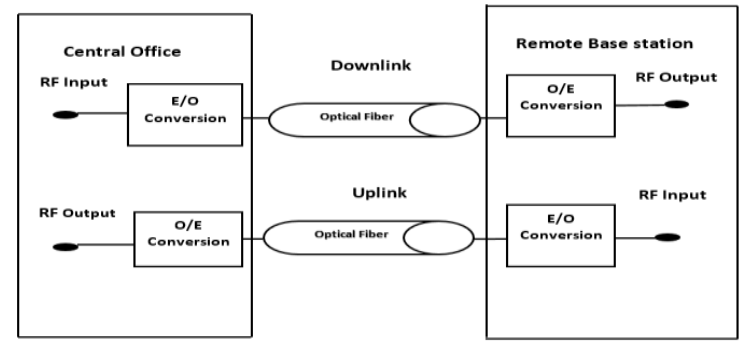

Figure 1.1: Radio-over Fiber Architecture [3]

\subsection{Advantages of RoF}

Some of the advantages and benefits of the RoF technology compared with electronic signal distribution are given below : (i) Low Attenuation loss: optical fiber offers very low loss hence RoF technology can be used as a backbone for transporting microwave or millimeter waves from central station to base stations (ii) Large Bandwidth: Optical fibers offer enormous bandwidth however, todays state-of-the art commercial systems utilize only a fraction of this capacity (iii) Low RF power remote antenna units (RAUs) has many benefits such as Increased battery life of mobile terminals, Low generated interference, Easier frequency/network planning and relaxed human health issues (iv) Dynamic resource allocation: For instance in a RoF distribution system for GSM traffic, more capacity can be allocated to an area during busy hours and then re-allocated to others areas. (v) Centralized upgrading: As most of the signal processing operations take place in central station the remote base station is simpler. (vi) Line of sight (LOS) operation (multipath fading effects are minimized) as the signals are carried out by optical fiber the losses that occur during wireless transmission systems are avoided to a greater extend. (vii) Immunity to Radio Frequency Interference: is a very attractive property of the optical fiber, which also provides privacy and security [14].

\section{MULTIPLEXING TECHNIQUES}

Multiplexing techniques play an important role in achieving high spectral efficiency hence, to select an appropriate multiplexing technique with high spectral efficiency, enhanced performance and lower complex is a necessity for RoF systems. RF multiplexing techniques such as Sub-carrier multiplexing (SCM) is used and due to optical backend multiplexing techniques such as Time division multiplexing (TDM), orthogonal frequency multiplexing (OFDM) and Wavelength division multiplexing (WDM) are also used. The combination of two multiplexing techniques such as SCM and WDM has recently gained importance due to its high spectral efficiency and reduced complexity [7].

\subsection{A combination of both SCM based WDM RoF systems}

In order to take advantage of both the multiplexing techniques a combination of SCM based WDM systems are used. SCM systems are more mature hence, RF modulation, filtering can be done in the electrical domain whereas WDM systems provides enormous bandwidth. As shown in figure 2.1 SCM is used as electrical side multiplexing whereas WDM is used as an optical side multiplexing. On the receiver side the optical WDM systems are de-multiplexed and detected by a photodetector to respective wavelengths which are further demultiplexed into respective RF as shown in figure 2.2. The combination of SCM based WDM systems may provide a flexible platform for high-speed optical transport networks with high optical bandwidth efficiency and high dispersion tolerance $[18,20]$.

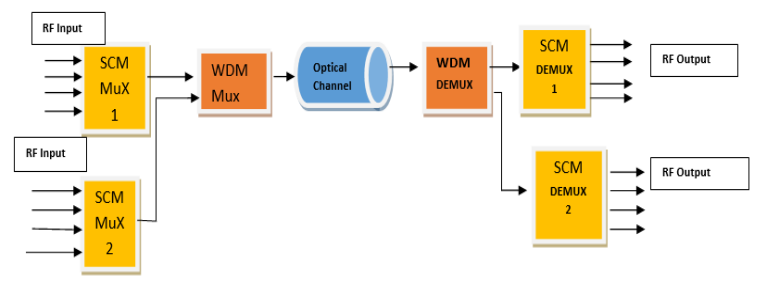

Figure 2.1: A combination of SCM-WDM RoF systems [18]

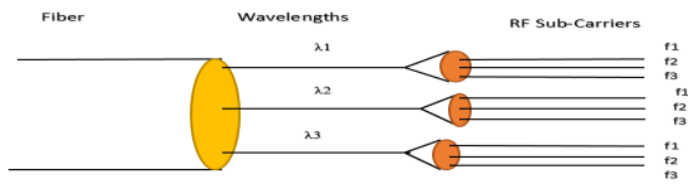

Figure 2.2: De-multiplexing of WDM and SCM in the receiver side of RoF systems [16].

\subsection{Frequency up and down conversion}

Frequency up and down conversion is a technique where instead of RF signal IF signal is transmitted over optical fiber. The transmitted IF signal is free from the fiber dispersion effect. There are many reported frequency conversion techniques using an external modulator, optical heterodyne, optical transceiver, using nonlinear effects such as Four-wave mixing (FWM) [12], Stimulated Brillouin scattering [11], using mixers such as Heterojunction bi-polar transistor (HBT) [21], High electron mobility transistor (HEMT), Avalanche photodiodes etc.

\subsubsection{Frequency conversion using Mixers}

Electronic mixers such as Si-Ge based HBTs are used on the receiver side where the frequency is up-converted before transmitting wirelessly to the end users. The optical signal is first demodulated using photo-detector in the receiver end and then it is up-converted to the required radio frequency level. Any device used as a mixer must have strong non-linearity, low noise, low distortion and adequate frequency response. An electrical mixer consists of two input port and one output port as shown in figure 6. In which one input is given as IF input signal and the other input port is given a pump waveform which is known as local oscillator (LO) port is required to pump the mixer. LO signal is the strongest and hence it is used to transform IF signal to RF during downlink and RF to IF signal during uplink [25].

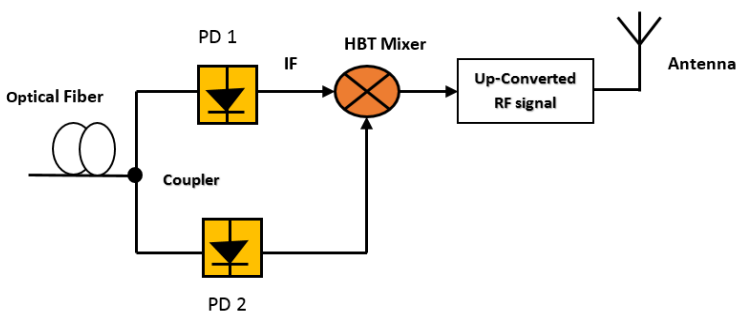

Figure 2.3: Frequency up-conversion at receiver side using an HBT mixer [25]. 


\section{SYSTEM DESIGN}

Our proposed RoF system is simulated using Optisystem software 7.0.Central System (CS) which consists of four pseudo random sequence bit generator generating binary signals which are converted into electrical by using Phaseshift keying modulator (PSK) in this way four electrical carrier signals are generated from, which two signals are electrically multiplexed using a Combiner 1 as shown in figure 3.1 which are further converted into an optical signal by externally modulating it with a continuous wave (CW1) laser and a Mach-Zehnder Modulator (MZM1) the central wavelength of CW1 laser is $1551 \mathrm{~nm}$.

The other two signals are further electrically multiplexed using Combiner 2 which is further converted into an optical signal by external modulation using CW2 and MZM2 with a central wavelength of $1552 \mathrm{~nm}$. These two optical signals are of wavelengths $1551 \mathrm{~nm}$ and $1552 \mathrm{~nm}$ which are further multiplexed using Wavelength division multiplexer (WDM). In our proposed system, we have used wavelength which falls under C-Band where attenuation is minimum and hence it achieves the longest range. The wavelength multiplexed signal is carried over a single mode fiber (SMF) for a distance of $50 \mathrm{~km}$ with a data rate fixed at $2 \mathrm{Gbps}$, then it is amplified using an optical amplifier with gain $20 \mathrm{~dB}$ and noise figure $4 \mathrm{~dB}[20]$.

\subsection{IF based RoF system}

Instead of modulating the RF signal with an optical signal we are using IF signal. IF (frequency less than $30 \mathrm{GHz}$ ) is modulated with optical signal. Four IF carrier signals which are applied in our system design are $5 \mathrm{GHz}, 10 \mathrm{GHz}, 15 \mathrm{GHz}$ and $25 \mathrm{GHz}$ As, shown in fig $3.1,5 \mathrm{GHz}$ and $10 \mathrm{GHz}$ PSK modulated signals are multiplexed using combiner 1 then, 15 $\mathrm{GHz}$ and $25 \mathrm{GHz}$ signals using combiner 2 . Then, these two signals are optically modulated using MZM and converted into wavelength $1551 \mathrm{~nm}$ and $1552 \mathrm{~nm}$ using CW1 and CW2 and further multiplexed into optical domain using WDM and passed through the fiber.

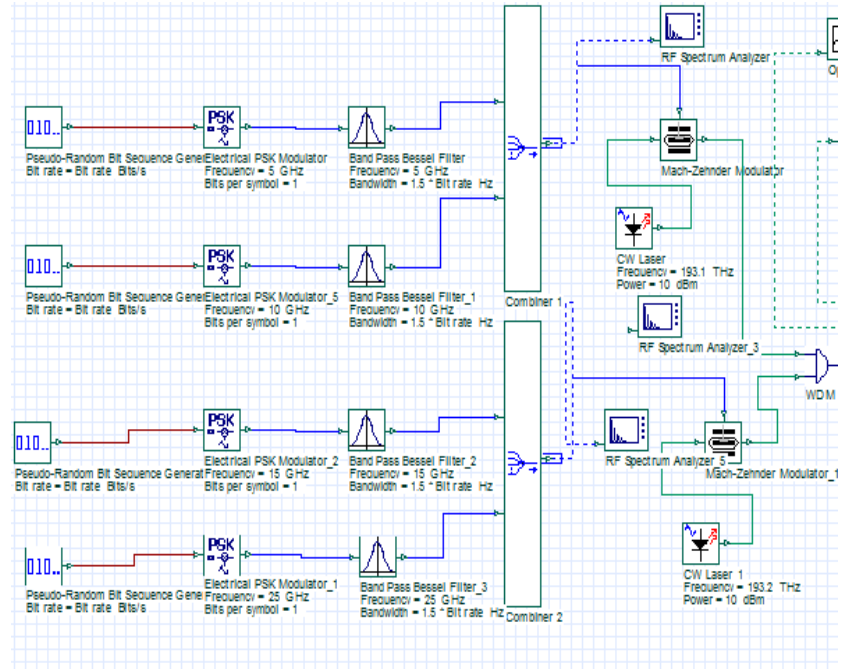

Figure 3.1: IFoF over fiber system.

BER, Q factor and Power value of the IF signals obtained at the receiver end are tabulated in table 1 .

Table 1: Intermediate frequency BER, $Q$ factor and power

\begin{tabular}{|c|c|c|c|}
\hline $\begin{array}{c}\text { Frequency } \\
\text { (in GHz) }\end{array}$ & BER & $\begin{array}{c}\text { Q factor (in } \\
\mathrm{dB})\end{array}$ & $\begin{array}{c}\text { Power (in } \\
\mathrm{dBm} \text { ) }\end{array}$ \\
\hline 5 & $4.57 \mathrm{E}-58$ & 16.0289 & -26 \\
\hline 10 & $6.34 \mathrm{E}-14$ & 7.40947 & -28 \\
\hline 15 & $8.88 \mathrm{E}-18$ & 8.50718 & -44 \\
\hline 25 & $3.70 \mathrm{E}-111$ & 22.3718 & -54 \\
\hline
\end{tabular}

\subsection{RF based RoF system}

In, our system instead of IF we are now modulating RF with an optical signal. Four RF signals used in our design are 15 $\mathrm{GHz}, 30 \mathrm{GHz}, 45 \mathrm{GHz}$ and $75 \mathrm{GHz}$. The system design is same as IFoF only instead of IF, RF signals are used as shown in figure 3.2. BER, Q-factor and power values of RF signals obtained at the receiver are tabulated in below table 2 .

Table 2: Radio frequency BER, $Q$ factor and power

\begin{tabular}{|c|c|c|c|}
\hline $\begin{array}{c}\text { Frequency (in } \\
\text { GHz) }\end{array}$ & BER & Q factor & Power (in dBm) \\
\hline 15 & $1.25 \mathrm{E}-22$ & 9.71721 & -44 \\
\hline 30 & $4.27 \mathrm{E}-06$ & 4.45093 & -52 \\
\hline 45 & 0.0302402 & 1.87724 & -60 \\
\hline 75 & 1 & 0 & -72 \\
\hline
\end{tabular}




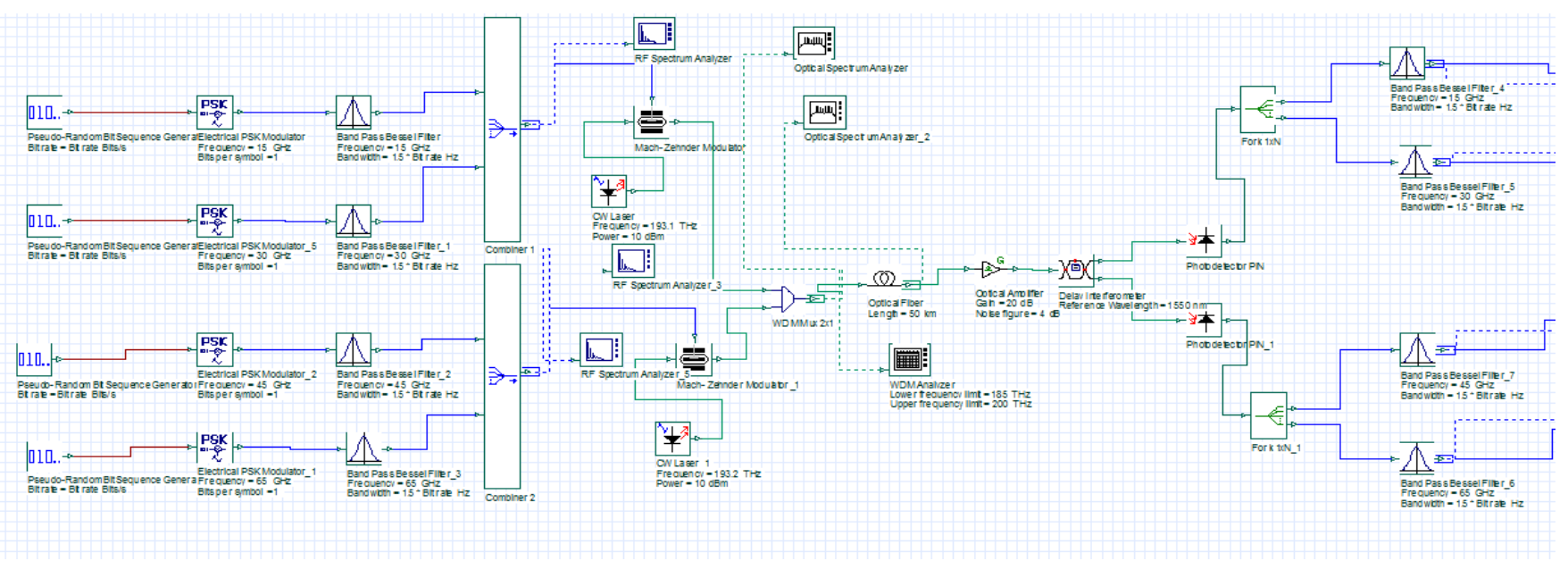

Figure 3.2: RFoF over fiber system.

\subsection{Comparison of IF and RF based RoF} system.

Comparison of IF over fiber and RF over fiber are done using the BER, Q-factor and power values obtained from the respective frequencies by keeping the data rate and fiber length constant at $2 \mathrm{Gbps}$ and $50 \mathrm{~km}$.

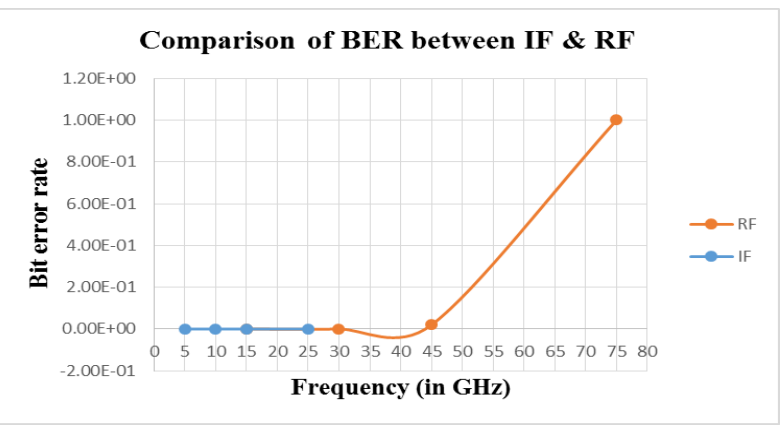

Figure 3.3: BER versus frequency.

From, the table 1 and 2 BER versus frequency graph has been plotted which shows that the BER for high frequencies (i.e. RF $15 \mathrm{GHz}, 30 \mathrm{GHz}, 45 \mathrm{GHz}$ and $75 \mathrm{GHz}$ ) are more whereas, BER for low frequencies such as IF $(5 \mathrm{GHz}, 10 \mathrm{GHz}, 15 \mathrm{GHz}$ and $25 \mathrm{GHz}$ ) is less. The BER value for RF increases steadily as the frequency increases. Whereas, the BER for IF is constant and lesser than RF.

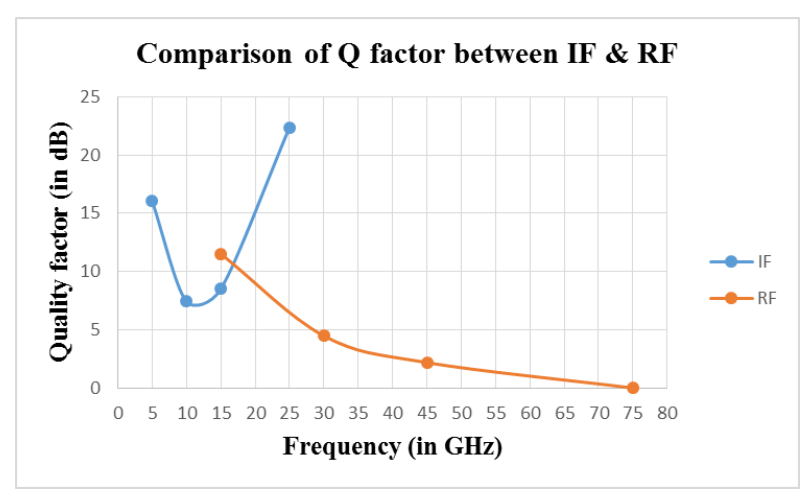

Figure 3.4: Q-factor versus frequency
From, the graph shown in figure 3.4 we can conclude that Qfactor value for IF signal from $5 \mathrm{GHz}$ decreases till $10 \mathrm{GHz}$ after that it increases gradually for $15 \mathrm{GHz}$ and $25 \mathrm{GHz}$. Whereas, in case of RF signal the Q-factor decreases steadily from $15 \mathrm{GHz}$ till $75 \mathrm{GHz}$. IF frequencies have acceptable Qfactor level whereas, for RF signals Q-factor value decreases sharply. Q-factor value for $45 \mathrm{GHz}$ and $75 \mathrm{GHz}$ is too low and below expected level.

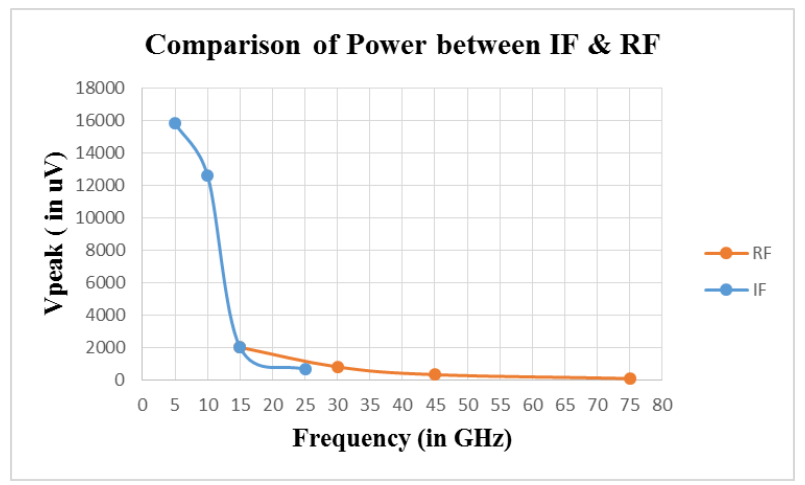

Figure 3.5: Power versus frequency.

The power value for IF and RF is expressed in terms of ultravolts. Power for IF signal is better than RF. Dynamic range is very important in wireless systems hence, power is an important factor describing signals.

From the above three graphs in figure 3.3, 3.4 and 3.5 we can conclude that IF over fiber is more beneficial than sending RF over fiber. But, the practical difficulty in sending these IF over fiber signals is that they need up-conversion in the receiver end (i.e. A remote base stations) before, being transmitted wirelessly. These Up-conversion while downlink and Down-conversion while uplink makes the receiver end more complex. Hence, there was a need for up-conversion technique. We have used HBT (Hetero-junction bipolar transistor) mixer in our system due, to its less complexity, cost effectiveness and high conversion gain and its usage can be extended up-to millimeter wave signals range. 


\section{FREQUENCY UP-CONVERSION USING HBT MIXER}

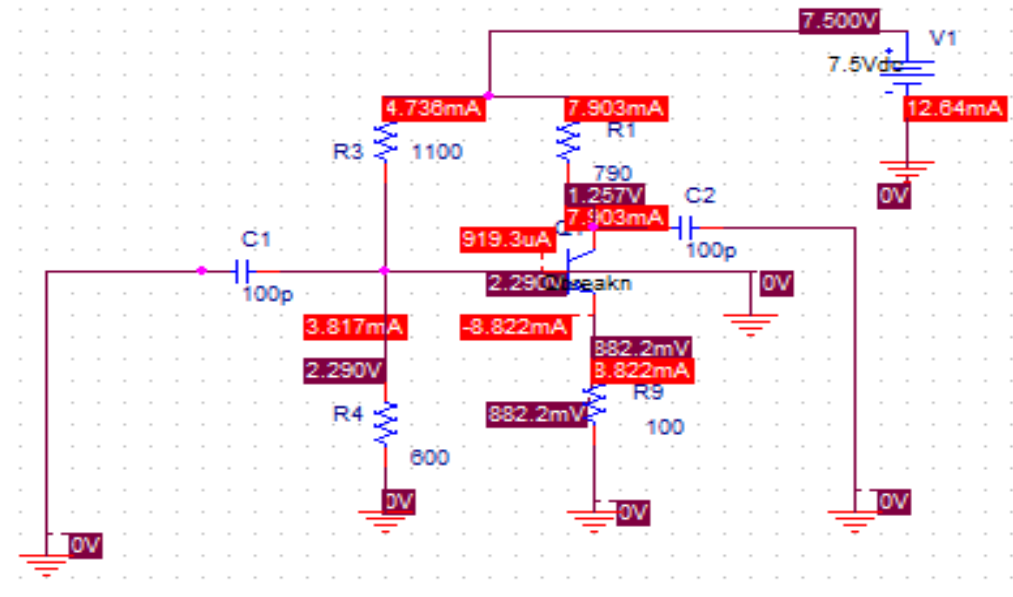

Figure 4.1: DC bias of HBT mixer circuit.

The design steps are divided into 5 parts. These are the DC biasing of the mixer circuit, S-parameters measurement of RF and IF, input matching, output matching and final design verification.

In this work, Agilent Hetero-junction transistor has been used the PSPICE parameters used for modelling the transistor has been tabulated below in table 3 . The DC biasing point obtained after simulation is as shown in figure 4.1 was employed with 7.5 VDC bias voltage. From the simulation, VCE $=1.25 \mathrm{~V}$ and $\mathrm{IC}=7.9 \mathrm{~mA}$ operating point were obtained.

Scattering parameter, or normally known as S-parameter, is one of the crucial requirements in designing any circuit involving with active element such as a transistor. It is essential to determine the S-Parameter so that the maximum power transferred to the circuit, or also known as, circuit matching can be done appropriately.

In our work, we are only interested with the S- and Zparameters of the desired frequency table 3 below shows the summarized S- and Z-parameters of the main RF mixer designed using HBT. Z-parameters were obtained from the Sparameters to perform the matching transformation. From Zparameter the impedance matching is obtained at desired frequencies and the input, output ports were designed in order to obtain maximum power transfer.

Table 3: S- parameters and Z-parameters for the desired frequencies.

\begin{tabular}{|c|c|c|c|c|}
\hline \multirow{2}{*}{ Frequency in GHz } & S11 & S22 & Z11 & Z22 \\
\hline $5 \mathrm{GHz}$ & $0.453+0.255 \mathrm{j}$ & $0.599-0.0492 \mathrm{j}$ & $100+70 \mathrm{j}$ & $70+45 \mathrm{j}$ \\
\hline $10 \mathrm{GHz}$ & $0.591+0.198 \mathrm{j}$ & $0.559-0.0492 \mathrm{j}$ & $148+96 \mathrm{j}$ & $174-25 \mathrm{j}$ \\
\hline $15 \mathrm{GHz}$ & $0.633-0.110 \mathrm{j}$ & $0.566-0.318 \mathrm{j}$ & $200-75 \mathrm{j}$ & $100-110 \mathrm{j}$ \\
\hline $20 \mathrm{GHz}$ & $0.567-0.0475 \mathrm{j}$ & $0.551-0.319$ & $178-25 \mathrm{j}$ & $98-105 \mathrm{j}$ \\
\hline $25 \mathrm{GHz}$ & $0.503-0.0373 \mathrm{j}$ & $0.539-0.325 \mathrm{j}$ & $150-15 \mathrm{j}$ & $95-102 \mathrm{j}$ \\
\hline $30 \mathrm{GHz}$ & $-0.299+0.167 \mathrm{j}$ & $-0.0583+0.195 \mathrm{j}$ & $25.7+9.75 \mathrm{j}$ & $41.4+16.8 \mathrm{j}$ \\
\hline $45 \mathrm{GHz}$ & $-0.0223+0.170 \mathrm{j}$ & $0.273+0.0986 \mathrm{j}$ & $45.2+15.8 \mathrm{j}$ & $85+18.3 \mathrm{j}$ \\
\hline $50 \mathrm{GHz}$ & $0.204+0.242 \mathrm{j}$ & $0.302+0.106 \mathrm{j}$ & $65.0+35.58 \mathrm{j}$ & $90.3+21.2 \mathrm{j}$ \\
\hline $75 \mathrm{GHz}$ & $0.627-0.150 \mathrm{j}$ & $0.332+0.120 \mathrm{j}$ & $181-93.1 \mathrm{j}$ & $95.5+26.6 \mathrm{j}$ \\
\hline
\end{tabular}




\subsection{Up-conversion of $15 \mathrm{GHz}$ signal using IF $5 \mathrm{GHz}$ and LO signal $10 \mathrm{GHz}$ :}

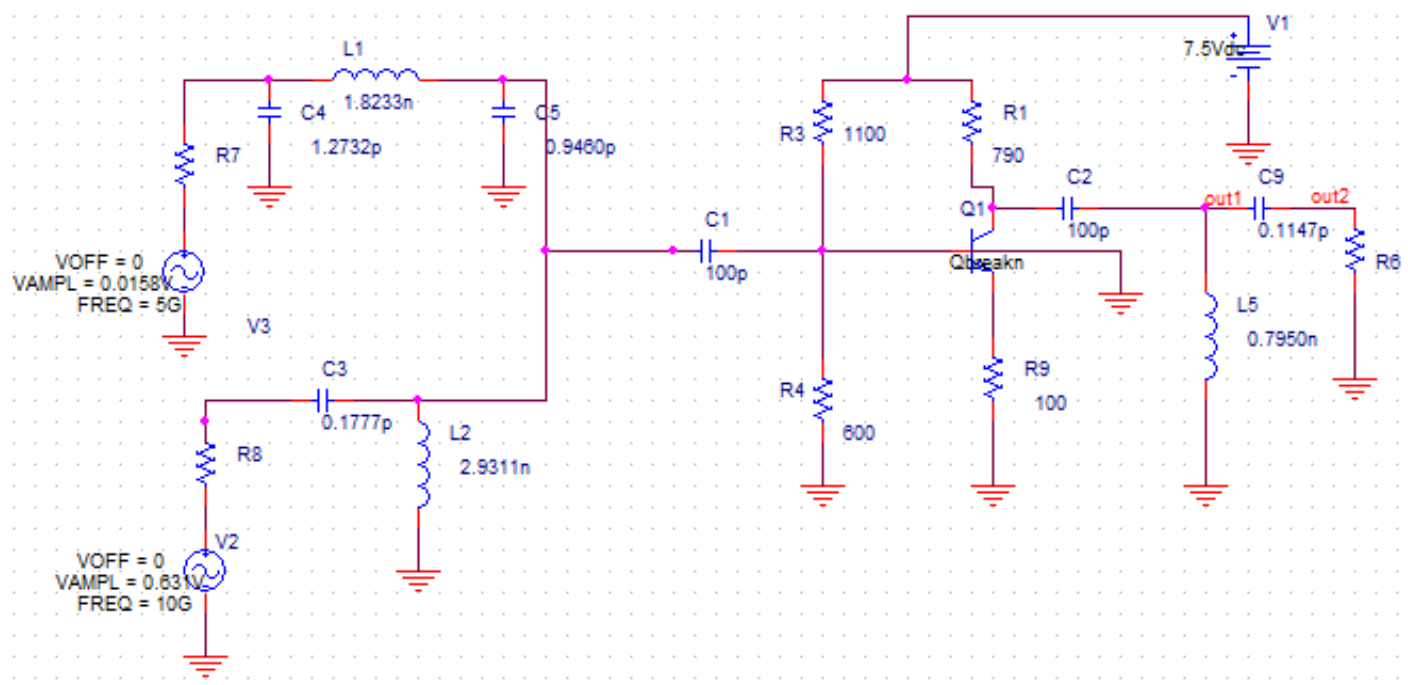

Figure 4.2: Schematic diagram of the Up-conversion mixer circuit for RF $15 \mathrm{GHz}$ [25]

The Schematic diagram of the mixer circuit is depicted in Fig. 4.2. It consists of three ports which are IF and LO ports as the input ports and RF port as the output port. LO power must be higher than IF power since it acts as a driver or pumping signal to control the switching of the mixer. In designing both the input ports, the desired frequencies with their Sparameters should be considered. In order to perform the matching network of IF port, we would like to match the IF input impedance, $\mathrm{Z} 11$ for an IF frequency of $5 \mathrm{GHz}$ found in Table 3 with a $50 \Omega$ matching impedance. Similarly for the LO port, we would like to match the LO input impedance, Z11for the LO frequency of $10 \mathrm{GHz}$ that is also found in Table 3 with a $50 \Omega$ matching impedance. We will consider the load or the output impedance instead of the input impedance of the RF port. Therefore, we transformed a $50 \Omega$ to match to the RF load impedance, Z22 for RF frequency of $15 \mathrm{GHz}$ as obtained in Table 3. In carrying out the impedance matching procedure, we are assuming the transistor to be operating in a quasi-linear mode. It is nonlinear, so as to produce the mixing effect, yet the linearity is small enough so that the usual linear procedure and the concept of impedance can be applied. The above system setup is simulated using PSPICE software in time domain.

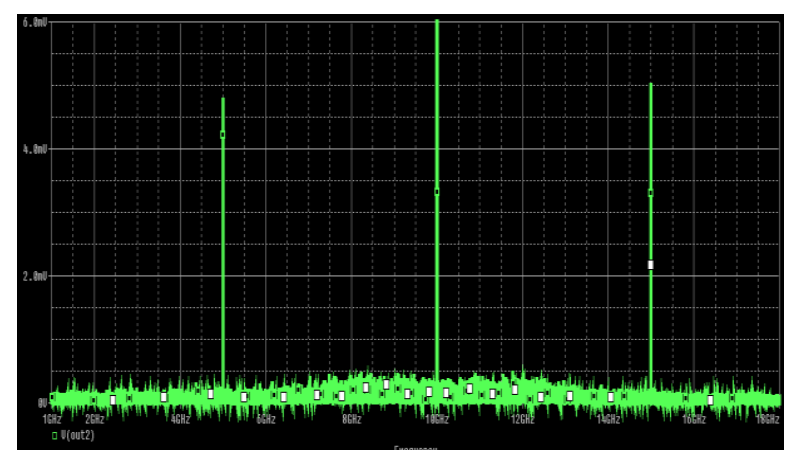

Figure 4.3: Simulated RF output spectrum at $15 \mathrm{GHz}$.
The output probe window of the PSPICE transient analysis with frequency in its $\mathrm{x}$-axis and Vpeak voltage in its y axis, which is selected to be $\mathrm{V}$ (out2) which displays the voltage from the node OUT2 has been shown in figure 4.3. The above figure shows the Vpeak value of the frequencies $5 \mathrm{GHz} \mathrm{IF}, 10$ $\mathrm{GHz} \mathrm{LO}$ frequency both are the input frequencies and $15 \mathrm{GHz}$ which is the up-converted RF output frequency.

\subsection{Up-conversion of $\mathrm{RF}$ at $30 \mathrm{GHz}$}

The output spectrum of the HBT mixer using IF at $10 \mathrm{GHz}$ and $\mathrm{LO}$ at $20 \mathrm{GHz}$. The input, LO and output port of the mixer are matched using the impedance values tabulated in table 3. The RF output spectrum obtained in the output probe is shown in figure 4.4 .

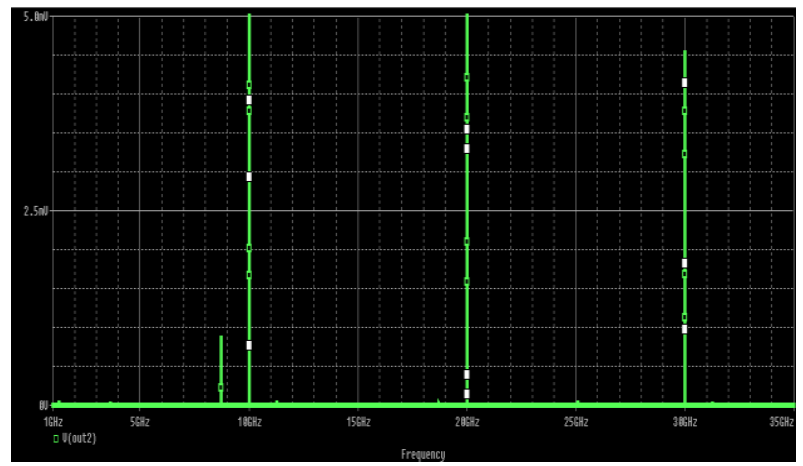

Figure 4.4: Simulated RF output spectrum at $30 \mathrm{GHz}$

\subsection{Up-conversion of $\mathrm{RF}$ at $45 \mathrm{GHz}$}

The output spectrum of the HBT mixer using IF at $15 \mathrm{GHz}$ and $\mathrm{LO}$ at $30 \mathrm{GHz}$. The input, LO and output port of the mixer are matched using the impedance values tabulated in table 3. The RF output spectrum obtained in the output probe is shown in figure 4.5. 


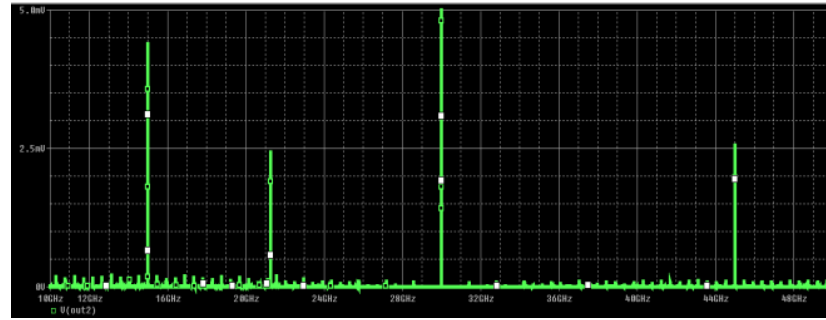

Figure 4.5: Simulated RF output spectrum at 45 GHz.

\subsection{Up-conversion of RF at $75 \mathrm{GHz}$}

The output spectrum of the HBT mixer using IF at $25 \mathrm{GHz}$ and $\mathrm{LO}$ at $50 \mathrm{GHz}$. The input, LO and output port of the mixer are matched using the impedance values tabulated in table 3. The RF output spectrum obtained in the output probe is shown in figure 4.6.

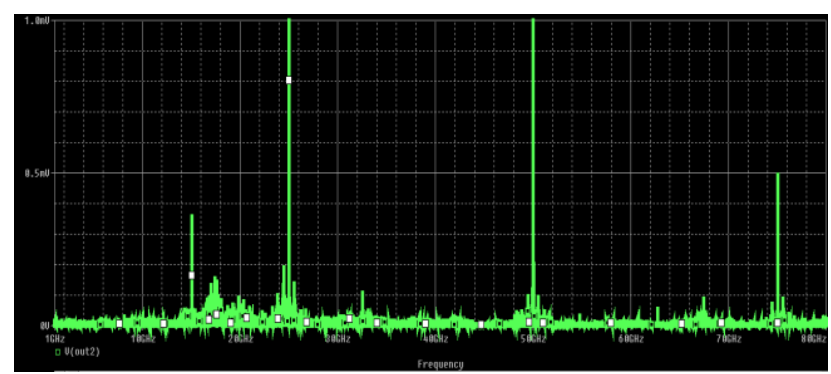

Figure 4.6: Simulated RF output spectrum at 75 GHz.

\subsection{Comparison of Conversion losses}

Table 4: Conversion gain for different RF signals

\begin{tabular}{|c|c|c|c|}
\hline $\begin{array}{c}\text { Frequency } \\
\text { (in GHz) }\end{array}$ & $\begin{array}{c}\text { Input } \\
\text { power } \\
\text { ( in dBm) }\end{array}$ & $\begin{array}{c}\text { Output RF } \\
\text { power } \\
\text { (in dBm) }\end{array}$ & $\begin{array}{c}\text { Conversion } \\
\text { gain } \\
\text { (in dB) }\end{array}$ \\
\hline $\mathrm{IF}=5$ & $\mathrm{IF}=-26$ & -31.4 & -4.4 \\
$\mathrm{LO}=10$ & $\mathrm{LO}=10$ & & \\
$\mathrm{RF}=15$ & & -38 & -10 \\
\hline $\mathrm{IF}=10$ & $\mathrm{IF}=-28$ & & \\
$\mathrm{LO}=20$ & $\mathrm{LO}=5$ & & \\
$\mathrm{RF}=30$ & & & \\
\hline $\mathrm{IF}=15$ & $\mathrm{IF}=-44$ & & \\
$\mathrm{LO}=30$ & $\mathrm{LO}=3$ & -42 & \\
$\mathrm{RF}=45$ & & & \\
\hline $\mathrm{IF}=25$ & $\mathrm{IF}=-54$ & & \\
$\mathrm{LO}=50$ & $\mathrm{LO}=5$ & -56 & \\
$\mathrm{RF}=75$ & & & \\
\hline
\end{tabular}



Figure 4.7: Comparison of conversion losses.

A comparison of conversion losses of the mixer operated at different IF frequencies to get the desired RF frequency at different LO power is presented using a graph in figure 5.1. The graph is plotted using the conversion loss/ gain, which is the difference between the inputs IF power to the output RF power obtained after conversion. The conversion loss for RF at $15 \mathrm{GHz}$ increases from $\mathrm{LO}$ power of $0 \mathrm{dBm}$ to $2 \mathrm{dBm}$ after that it reduces and maintains a lowest conversion loss at LO power $10 \mathrm{dBm}$. The conversion loss for $30 \mathrm{GHz}$ is fluctuating till LO power of $5 \mathrm{dBm}$. Similarly, for $45 \mathrm{GHz}$ it is low till LO power of $3 \mathrm{dBm}$, we obtain a conversion gain of $2 \mathrm{~dB}$ at this point but after that it starts increasing. For, $75 \mathrm{GHz}$ till LO power of $5 \mathrm{dBm}$ conversion loss decreases and after that it starts increasing gradually. The better conversion gain obtained for different RF frequencies are tabulated in table 4 .

\section{CONCLUSION}

IF over fiber has low BER, better Quality factor and high dynamic range than RF over fiber but, the practical difficulty in IF over fiber is that they need up-conversion in the remote base station. Simple and less complex receiver end of the remote base station is the main requirement of RoF systems. Hence, numerous techniques have been introduced for frequency up-conversion in the receiver end.

We have up-converted four electrical signals from IF frequency $5 \mathrm{GHz}, 10 \mathrm{GHz}, 15 \mathrm{GHz}$ and $25 \mathrm{GHz}$ for $\mathrm{RF}$ frequency $15 \mathrm{GHz}, 30 \mathrm{GHz}, 45 \mathrm{GHz}$ and $75 \mathrm{GHz}$ using a HBT electrical mixer due, to its less complexity, cost effectiveness and extended usage up-to millimeter wave signal range. Better mixing is obtained in the up-conversion of $\mathrm{RF}$ at $45 \mathrm{GHz}$ with a conversion gain of $2 \mathrm{~dB}$ at a $\mathrm{LO}$ power of $3 \mathrm{dBm}$.

\section{REFERENCES}

[1] Anthony Ng'oma,"Radio-over-Fiber Technology for Broadband Wireless Communication Systems", Doctoral Thesis, University of Eindhoven, 2005.

[2] Tong Shao, "Study of converged $60 \mathrm{GHz}$ Radio over Fiber WDM-PON Access network", Ph.D. thesis, University of Grenoble, 2007.

[3] Edem Kodjo, "Performance Investigation of OFDM Technology for RoF systems", Master degree thesis, Wuhan University of Technology, 2012.

[4] Wong Sie Woo, "Development Of Ofdm in Wdm-Radio Over Fiber Access Network", Master degree thesis, Tun Hussein Onn University of Malaysia, July 2012. 
[5] Mahyuddin Bin Arsat, "Simulation and performance analysis of Sub-carrier multiplexed Radio over fiber system", University of Malaysia, Dec2007.

[6] Joffray Guillory, "Radio over Fiber for the future Home Area Networks", Doctoral Thesis, University of ParisEst, October 30, 2012.

[7] Rongqing Hui et. A, "Subcarrier multiplexing for High speed optical transmission", Journal of lightwave Technology, vol.20, no.3, pp 417-428, 2002

[8] David Wake, Anthony Nkansh, and Nathan J.Gomes, Senior Member IEEE, "Radio over fiber Link design for next generation wireless systems", Journal of lightwave Technology, vol.,28,No.16,August 15,2010.

[9] Xavier Fernando, "Radio over Fiber an Optical Technique an Optical Technique for Wireless Access", Ryerson Communications Lab Toronto, Canada.

[10] B. Charbonnier, H.Le Bras, P. Urvoas, Q.T. N'Guyen, M. Huchard, A. Pizzinat, Upcoming perpectives and future challenges for RoF, Next Generation optical access, 2007.

[11] N. A. Awang, H. Ahmad, S. F. Norizan, M.Z. Zulkifli, Z.A.Ghani and S. W. Harun, "An All-Optical Frequency Up/Down-Converter Utilizing Stimulated Brillouin Scattering In A Trf And Def For Rof Application", Journal of Science and Technology.

[12] Hyoung-Jun Kim and Jong-In Song, "All optical frequency down-conversion technique utilizing a FWM effect in a single semiconductor optical amplifier for WDM-RoF applications", Optics Express, 8047 Vol.20, 26 March 2012.

[13] Artech house, 2002. Radio-over-Fiber Technologies for mobile communication networks, Link design for next generation wireless systems", Journal of lightwave Technology, vol., 28, No.16, August 15,2010.

[14] R.Karthikeyan, Dr S.Prakasam, "A Survey on Radio over Fiber (RoF) for Wireless Broadband Access Technologies", International Journal of Computer Applications, February 2013.

[15] Ajay kumar Vyas, Dr. Navneet Agarwal, "Radio over Fiber: Future Technology of Communication", International Journal of Emerging Trends \& Technology in computer science (IJEITCS), Volume 1, Issue 2, JulyAugust 2012.

[16] Al-Raweshidy H. and Komaki S., "Radio over fiber technologies for mobile communication networks," Artech House Publisher, ISBN 1-58053-148-2, 2002.

[17] Arsat M. and Idrus S. M., "Sub Carrier Multiplexed for Radio over Fiber: Modeling and Performing Analysis," presented at the International Conference on Robotics, Vision, Information and Signal Processing 2007 (ROVISP07), pp 96-99, Penang, Malaysia, 2007.

[18] Vimala Reddy, Dr Lochan Jolly, "Radio over fiber technology an integration of microwave and optical network for wireless access", International journal of computer application, 2013.

[19] Zhensheng Jia, Student Member, IEEE, Jianjun Yu, Senior Member, IEEE, and Gee-Kung Chang, Fellow, IEEE" A Full-Duplex Radio-Over-Fiber System Based on Optical Carrier Suppression and Reuse" IEEE photonics technology letters, vol. 18, no. 16, august 15 , 2006.

[20] S. Vimala Reddy, Dr Lochan Jolly, "Simulation and performance analysis of Sub-carrier based Wavelength multiplexed radio over fiber system", International J. of Engg. Research \& Indu. Appls. (IJERIA), ISSN 09741518, Vol.8, No. II (May 2015), pp. 1-1.

[21] J. P. Comeau and J. D. Cressler, "A 28-GHz SiGe upconversion mixer using a series- connected triplet for higher dynamic range and improved IF port return loss," Solid-State Circuits, IEEE Journal of, vol. 41, pp. 560$565,2006$.

[22] M. No Gil, et al., "A low voltage SiGe HBT upconversion mixer for $5.8 \mathrm{GHz}$ WLAN," in Radio and Wireless Symposium, IEEE, 2006, pp. 435-438.

[23] J. Joo-Yong, et al., "High linear single-ended upconversion mixer using $\mathrm{InGaP} / \mathrm{GaAs}$ HBT process," in Microwave Conference Proceedings, 2005. APMC 2005. Asia-Pacific Conference Proceedings, 2005, p. 4 pp.

[24] M. Huber, et al., "Ultra low power $24 \mathrm{GHz}$ HBT mixer," in Microwave and Optoelectronics, SBMO/IEEE MTT-S International Conference, 2005, pp. 24-27.

[25] Norliza Mohamed, Sevia Mahdaliza Idrus, Abu Bakar Mohammad, Syamsuri Yaakob, "Development and Demonstration of $12.4 \mathrm{GHz}$ SiGe HBT Mixer for Radio over Fiber Applications" Wseas Transactions On Circuits And Systems, Issue 10, Volume 11, October 2012.

[26] Jacob Lasri, Y. Betser, Victor Sidorov, S. Cohen, D. Ritter, M. Orenstein, and Gadi Eisenstein, Fellow,IEEE, "HBT Optoelectronic Mixer at Microwave Frequencies: Modeling and Experimental Characterization", Journal Of Lightwave Technology, Vol. 17, No. 8, August 1999.

[27] Yoram Betser, Dan Ritter, C. P. Liu, A. J. Seeds, and A. Madjar," A Single-Stage Three-Terminal Heterojunction Bipolar Transistor Optoelectronic Mixer", Journal of Lightwave Technology, VOL. 16, NO. 4, APRIL 1998. 